\title{
EFFECT OF BREAKFAST SKIPPING ON BODY MASS INDEX IN ADOLESCENT UNIVERSITY GIRLS
}

Noor Fatima ${ }^{a}$, Zirwa Noor ${ }^{b}$, Swaira Shafique ${ }^{c}$

${ }^{a}$ Nutritionist, Madinah Teaching Hospital Faisalabad.

${ }^{b}$ Women Medical Officer, BHU Faisalabad.

'Pharmacist District Headquarter Hospital Talagang.

\begin{abstract}
:
BACKGROUND \& OBJECTIVE: Breakfast is considered as important meal of the day and it should provide $25 \%$ of total energy intake including all five food groups. Breakfast skipping is common in adolescents and it is associated with changes in Body Mass Index (BMI) and cognitive abilities. Breakfast skipping enhances appetite throughout the remaining day which leads to over eating resulting in overweight and obesity. Addition of breakfast is useful plan of action to improve satiety, reduced food motivation and improve diet quality. Eating breakfast regularly has association between both with less mental distress and healthy life style. For this purpose, this study was designed to determine the prevalence of breakfast skipping in adolescent's university girls and its effect on their Body Mass Index (BMI).

METHODOLOGY: For the current research, 200 individuals were selected from different departments of The University of Faisalabad. Questionnaire was developed and height, weight and dietary history were measured. The data obtained from the study was tabulated and statistically analyzed by applying Analysis of Variance (ANOVA) and Least Significant Difference (LSD).

RESULTS: BMI Mean and Standard deviation of 200 university adolescent girls depending on the breakfast consumption is 22.34. Results indicated that adolescents who skipped breakfast more than three times per week had height value of BMI $\left(24.96 \mathrm{~kg} / \mathrm{m}^{2}\right)$, which followed by those who were regularly skipping breakfast $23.30 \mathrm{~kg} / \mathrm{m}^{2}$. Skipping of breakfast has significant effect on increasing the Body Mass Index (BMI) in university adolescent girls.
\end{abstract}

CONCLUSION: Breakfast skipping resulted in increased BMI in university adolescent girls.

KEY WORDS: Breakfast, Academic performance, Body Mass Index, Obesity.

doi: https://doi.org/10.37723/jumdc.v11i2.407

\section{How to cite this:}

Fatima N, Noor Z, Shafique S. EFFECT OF BREAKFAST SKIPPING ON BODY MASS INDEX IN ADOLESCENT UNIVERSITY GIRLS. jumdc. 2020; 11(2):9-15.

doi: https://doi.org/10.37723/jumdc.v11i2.407

This is an Open Access article distributed under the terms of the Creative Commons Attribution License (http://creativecommons.org/licenses/by/4.0), which permits unrestricted use, distribution, and reproduction in any medium, provided the original work is properly cited. 


\section{INTRODUCTION:}

Adolescence is a stage of life when growth and development occurs rapidly, so these stages are considered nutritionally vulnerable because they required adequate nutrition in this period of life. Nutrient requirement of adolescents are higher owing to the rapid development of psychosocial, physiological and cognitive abilities. In this period, unhealthy eating practices such as increase in the consumption of junk food, eating outdoors, food choices with poor nutritional quality, irregular eating patterns especially breakfast skipping have long term health effects. ${ }^{[1]}$. Children and adults who eat breakfast have decreased risk of chronic diseases as compared to those who skip it $^{[2]}$.

Breakfast is contemporary part of the daily routine life. Skipping of breakfast makes children down in schools and job persons in their working areas. Choice of meal consumption in morning also has impact on overall wellbeing of persons ${ }^{[3]}$. Quantity and quality of breakfast play an important role in the development of chronic disease. Inadequate intake of breakfast is associated to increase the Body Mass Index (BMI) ${ }^{[4]}$.

It is observed that in developed countries, regular consumption of breakfast is inversely associated with excess weight and has direct association with better dietary and encouraged the physical activity behaviors. Daily consumption of breakfast helps in maintenance of the healthy body weight while decreases the risk of overweight and obesity. Intervention programs for regular breakfast consumption should be established to lower the overweight and obesity ${ }^{[5]}$. Skipping breakfast is linked with obesity, enhanced appetite throughout the remaining day and over eating. Obesity is associated with lessened cognitive and memory functions by altering the structure of the brain. Addition of breakfast specially protein rich (high protein) might be a useful plan of action to improve satiety, reduced food motivation and improve diet quality of overweight/obese teen age girls ${ }^{[6]}$. Irregular meal patterns are a main reason associated with severs gastrointestinal problems. Individuals who have odd meal timings and consumption behaviors have more

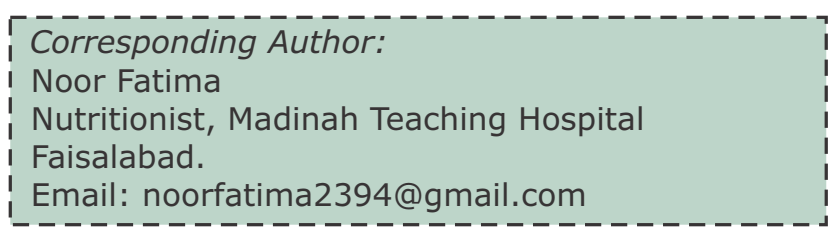

chances to developing the H.pylori infection which lead to chronic conditions like gastritis and gastric cancer ${ }^{[7]}$.

The skipping of breakfast has unhealthy effects on diet quality and increases the risk of metabolic disease. People who skip their breakfast have poor nutritive values throughout the day. They take most of their energy from unhealthy food sources that cause different metabolic syndromes ${ }^{[8]}$. The adequate intake of breakfast is linked to the healthier metabolic profile and it is practically good for younger one [9].

In young adolescent females the need of the Hemoglobin and Serum Ferritin increases due to the development of the secondary sexual characters and onset of the menstruation. Regular consumption of the breakfast has positive effects on the erum ferritin, hematocrit and hemoglobin when compared with adolescent girls who skipped breakfast on daily basis ${ }^{[10]}$. The omission of the major meal especially the breakfast and inadequate intake of energy, vitamins and minerals enhanced the risk of metabolic disorders, central adiposity and insulin resistance ${ }^{[11]}$. Regularly intake of breakfast and oral hygiene are important factors for healthy lifestyle ${ }^{[12]}$. Breakfast skipping has direct effect on the nutritional deficiencies in young adolescent females while the nutritional deficiencies relates to the many diseases like hypothalamic pituitary ovarian dysfunction. In this disease females observed premenstrual symptoms like premenstrual cramps and premenstrual abdominal pain. If these symptoms not cure on time females can develop further disease like dysamenhorrea and olligoamehorrea ${ }^{[13]}$.

Despite the effect of obesity and cognitive performance with breakfast skipping there are many other factors which are affected by the breakfast skipping in the adolescents. Changes in weight status causes the insulin insensitivity, psychological and hormonal disturbance which are indications to developing the chronic disease like diabetes, liver diseases and 
cardiovascular diseases etc. Young females who observed psychological issues due to obesity have more chances to develop the disease like bulimia nervosa and anorexia ${ }^{[14]}$. Eating inadequate meals at night and skipping day first meal (breakfast) leads to the increased chance of obesity and diabetes ${ }^{[15]}$.

Breakfast composition has effect on the adolescent's cognitive and academic performance. Consumption of the high glycemic cereals such as oatmeal in the breakfast provide the energy to the adolescent for the whole day while adolescents who eat low glycemic food has declined energy throughout the day. So, it is suggested that high fiber and high glycemic foods must be necessary to include in the breakfast to stay active and attentive to the whole day ${ }^{[16]}$. The purpose of the study was to evaluate the nutritional status of the adolescent girls. The healthy nutritional status is important for the whole life of the adolescents. Breakfast plays a key role in the health of the adolescents and has its effect on the BMI and their cognitive abilities. Breakfast skipping is root cause of the many problems of these days like obesity, bulimia nervosa, lethargy and cognitive disabilities. This study was designed to enhance the importance of breakfast in the adolescent life and evaluate the prevalence of the skipping of breakfast and its harmful effects on the academic performance and BMI.

\section{METHODOLOGY:}

The study was carried out in The University of Faisalabad. A total of 200 adolescent students were randomly selected from all schools of The University of Faisalabad. The study has been approved by the ethical review committee of University Medical \& Dental College, Faisalabad. The selected students were evaluated for their breakfast consumption and skipping pattern with their relation to body mass index (BMI), academic performance and intelligence quotient. The following data was collected from each individual. A questionnaire was developed and information was obtained regarding age, height, weight and BMI. Breakfast skipping parameters is shown in (Table-I).
Table-I: Breakfast skipping parameters.

\begin{tabular}{|c|c|}
\hline Parameters & $\begin{array}{c}\text { Frequency of } \\
\text { Breakfast skipping }\end{array}$ \\
\hline$T_{0}$ & Daily \\
\hline$T_{1}$ & Once a week \\
\hline$T_{2}$ & Twice a week \\
\hline$T_{3}$ & Thrice a week \\
\hline$T_{4}$ & More than three days \\
\hline$T_{5}$ & No skipping \\
\hline
\end{tabular}

$\mathrm{T}_{5}$ No skippingThe study was statistically analyzed by applying Analysis of Variance (ANOVA) and least significant Difference (LSD). The study was carried out in duration of two months. Sampling was convenient and random .The ages of the students were between 19-22 years.

Anthropometric measurements were done to determine the BMI value of the students using the following standard formula developed.

$$
\text { BMI = Weight }(\mathrm{kg}) / \text { Height }\left(\mathrm{m}^{2}\right)
$$

Anthropometric measurements of height and weight were measured by using specific guidelines recommended by WHO, (2007). Height was measured without shoes by using standard height chart. Weight was recorded in an upright standing position with minimum clothing to using mechanical weighing balance.

\section{RESULTS:}

In current study, we observed prevalence of breakfast skipping among adolescent university girls and analyzed the effect of breakfast skipping on different parameters including body mass index (BMI). BMI- Mean and standard deviation of university adolescent girls depending on the breakfast consumption is $22.34 \pm 3.037$ (Table-II). Findings showed the variable pattern of breakfast skipping. $32 \%$ lies on no breakfast, $9 \%$ are those who skip breakfast once in a week, $14 \%$ are those who skipped breakfast twice in a week, $14 \%$ are those who skipped breakfast thrice in a week, $7 \%$ are those who skipped breakfast more than thrice in a week, $24 \%$ are those who regular breakfast consumer (Figure-I). In this study 
statistical results indicated that adolescents who skipped the breakfast more than three times per week had highest value of BMI (24.96 $\mathrm{kg} / \mathrm{m}^{2}$ ) which followed by those who were regularly skipping the breakfast $23.30 \mathrm{~kg} / \mathrm{m}^{2}$. On the other hand BMI value $20.69 \mathrm{~kg} / \mathrm{m}^{2}$ was recorded for those adolescent girls who were eating breakfast on regular basis which support the hypothesis that breakfast skipping leads to overweight and obesity (Figure-II). Mean squares of breakfast skipping effect on BMI have been depicted in (Table-II) data showed that breakfast skipping has significant effect on body mass index. The breakfast skipping is directly proportional to body mass index. Increase in breakfast skipping increased the body weight as index and has negative effect on health which leads to further health consequences (Table-III).

Table-II: BMI of university adolescent girls depending on the breakfast consumption pattern.

\begin{tabular}{|c|c|}
\hline Factors & $\begin{array}{c}\text { Average } \pm \\
\text { Standard Deviation }\end{array}$ \\
\hline $\begin{array}{c}\text { Body mass index } \\
(\mathrm{BMI})\end{array}$ & $22.34 \pm 3.037$ \\
\hline
\end{tabular}

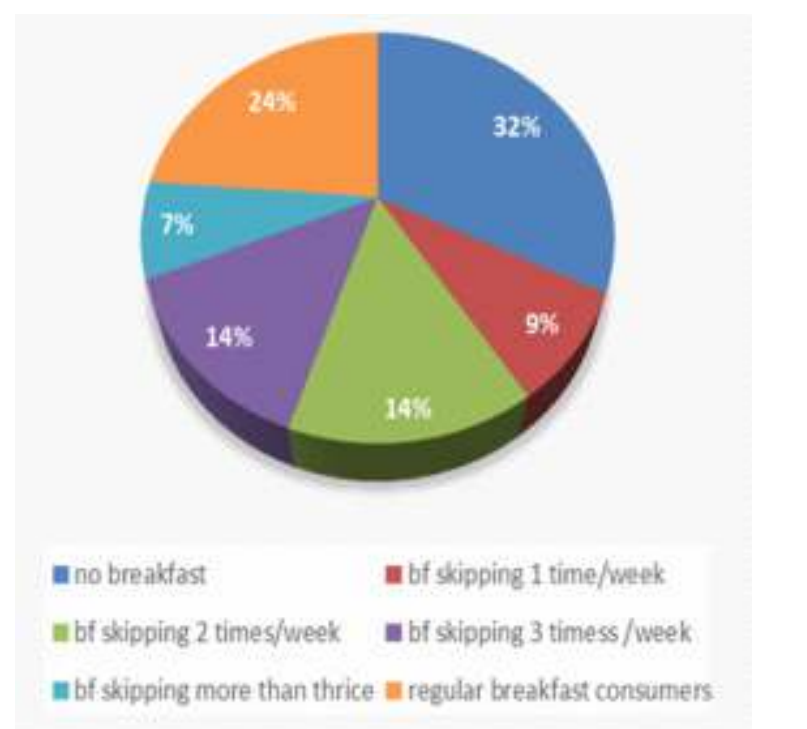

Figure-I: Shows prevalence of breakfast skipping among adolescent university girls. *BF=Breakfast.

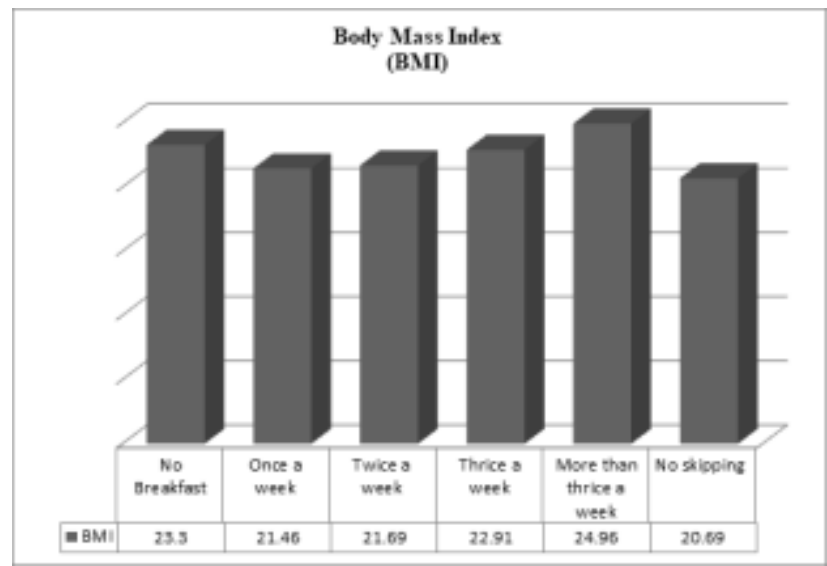

Figure-II: Effect of breakfast skipping on BMI.

Table-III: Analysis of Variance (ANOVA) for Body Mass Index (BMI).

\begin{tabular}{|c|c|c|c|c|}
\hline SOV & Df & SS & MS & $\begin{array}{c}\text { F- } \\
\text { Value }\end{array}$ \\
\hline Individual & 5 & 329.19 & 65.837 & $8.48^{* *}$ \\
\hline Error & 194 & 1506.97 & 7.767 & \\
\hline Total & 199 & & & \\
\hline
\end{tabular}

$* * *=$ Highly significant

DF=Degree of freedom

SS =Sum of Square

MS $=$ Mean square

The values within same column sharing similar alphabets do not differ significantly.

\section{DISCUSSION:}

This study was done to determine the prevalence of breakfast consumption and how breakfast skipping affect body mass index (BMI), academic performance intelligence quotient of the adolescent university girls. The study was carried out in The University of Faisalabad. 200 selected adolescent girls were analyzed. A questionnaire was developed in which questions were asked about the consumption and skipping frequency of the breakfast in the adolescent girls. It was observed that breakfast skipping is common among adolescent girls as $32 \%$ of the girls were skipping breakfast on daily basis and $23.5 \%$ consume breakfast regularly while other shows 
irregular pattern of breakfast consumption. Research work conducted ${ }^{[1]}$ suggested that prevalence of breakfast consumption on regular basis among adolescents is decreasing globally whereas breakfast consumption has been associated to lower risk of obesity and chronic diseases and improved cognition and nutrient intake. The prevalence of breakfast skipping among different groups of adolescent population of South Africa reported 13-36 \%. A cross sectional quantitative study carried among adolescents of 9 to 11 grades $(n=254)$ from seven secondary schools in Potchefstroom and its surroundings.

The results of present study also supported the results of the study conducted by ${ }^{[17]}$ that reported the prevalence of obesity increasing worldwide along with several health related complications. They assessed the children's behavior towards their breakfast habits, and their relationship to BMI in Greek adolescents and also breakfast skipping in relation to other health behaviors. The survey was conducted in the schools throughout Greece. Anthropometric measurements were performed on 6500 boys and 7778 girls, aged $13-19$ years. A questionnaire was developed to which questions regarding their eating habits and lifestyle. It was observed that breakfast skippers had high BMI against Breakfast consumers.

Present study suggested that breakfast skipping has significant effect on the Body mass index (Table-I). Body mass index increased with the increase in frequency of breakfast skipping. The skipping of the breakfast has negative effect on the BMI. Results of the present study depicted that adolescent students who frequently skip the breakfast had highest body mass index while on the other hand the students who were consuming breakfast daily basis showed lower body mass index which fall in the category of their normal BMI. The results of current research are in concordance with the outcomes of the research work which suggested that unhealthy dietary behavior leads to overweight, obesity and other metabolic problems $^{[18]}$. The objective of the study was to evaluate the relation of breakfast consumption and body composition. They assessed 236 adolescents with healthy appearance of ages between 12-19 years. Breakfast eating pattern showed that 50 percent on adolescents skip the breakfast. Gender -specific multivariate analysis showed adolescents those consume breakfast minimum five times in week had lower body weight, body fat mass total fat percent and BMI as compared to those who consume breakfast infrequently. Therefore they recommended that for maintenance of body weight regular breakfast consumption with healthy food choices should be promoted. A scientist found that the breakfast consumption lowers the risk of type 2 diabetes ${ }^{[19]}$. Composition of breakfast has role in the glycemic control of the diabetic patient. Inclusion of dietary fiber, Mediterranean oil and moderate dairy protein improved the insulin function in the patients. Scientists conducted a study to find out the effect of skipping breakfast on BMI and observed that the ratio of obesity is more in students who skip their breakfast in comparison with students having regular breakfast consumption patterns.

Sedentary life style, skipping breakfast is directly proportional to the BMI increased. The frequency of skipping breakfast as increased then BMI also increased ${ }^{[5]}$.

A study was conducted in Seoul women university, Seoul Korea with objective to find association between frequency of breakfast consumption and academic performance in healthy Korean adults ${ }^{[18]}$. In this study 75,643 adolescent participated, and association between breakfast consumption (per week) and academic performance was assessed by analyzing age, BMI, drinking frequency, family economics status, frequency of physical activity, muscular strength exercise and level of mental stress. They concluded that academic performance of both male and female individuals is positively correlated with frequency of breakfast consumption. The findings of the research found that BMI increased by the skipping of the breakfast. Breakfast has key importance in adolescent's life. Consuming the breakfast on the daily basis makes the adolescents more active and smart. A cohort study was conducted with 34,128 men and 49,282 women aged $40-79$ years ${ }^{[20]}$. The study was designed to assess the relation of breakfast skippers and consumer with circulatory diseases. The results of the study concluded that the skipping of breakfast has 
bad impact on lifestyle which cause increase mortality.

Present study finds that the main reason of increased BMI is skipping breakfast due to late night eating ${ }^{[21]}$.

\section{CONCLUSION:}

Breakfasts skipping negatively affect the cognitive abilities which relates to the attention and absenteeism and lower the academic performance while breakfast skipping causes the increase in the body mass index which leads to overweight and obesity and make the individual prone to certain obesity related health problems.

\section{CONFLICT OF INTEREST:}

All authors disclose no conflict of interest.

\section{GRANT SUPPORT \& FINANCIAL}

DISCLOSURES: None.

\section{REFERENCES}

1. So WY. Association between frequency of breakfast consumption and academic performance in healthy Korean adolescents. Iranian Journal of Public Health. 2013; 42(1): 25-32. PMID: 23514747

2. Ashraf S, Ali Z. Effect of Breakfast Skipping on Lipid Profile Parameters, Body Weight, and Metabolic Measures among University Going Adults. Journal of Nutrient \& Food Sciences. 2018; 8(693):2. DOI: 10.4172/2155-9600.1000693

3. Mekary RA, Giovannucci E, Willett WC, Van Dam RM, Hu FB. Eating patterns and type 2 diabetes risk in men: breakfast omission, eating frequency, and snacking. The American Journal of Clinical Nutrition. 2012; 95(5):1182- 1189. Doi: 10.3945/ ajcn.111.028209

4. Maki KC, Phillips-Eakley AK, Smith KN. The effects of breakfast consumption and composition on metabolic wellness with a focus on carbohydrate metabolism. Advances in nutrition. 2016
May;7(3):613S-21S. Doi:10.3945/an. 115.010314

5. Amigo-Vázquez I, Busto-Zapico R, ErrastiPérez JM, Pena-Suarez E. Skipping breakfast, Sedentarism and overweight in children. Psychology, health \& medicine. 2016;21(7):819-826. Doi:10.1080/ 13548506.2015.1131999

6. Karatzi K, Moschonis G, Choupi E, Manios Y, Skenderi KP, Grammatikaki E, et al. Latenight overeating is associated with smaller breakfast, breakfast skipping, and obesity in children: The Healthy Growth Study. Nutrition. 2017;33:141-144. DOI: 10.1016/j.nut.2016.05.010

7. Leidy $\mathrm{HJ}$, Ortinau LC, Douglas SM, Hoertel HA. Beneficial effects of a higher-protein breakfast on the appetitive, hormonal, and neural signals controlling energy intake regulation in overweight/obese, "breakfastskipping," late-adolescent girls. The American journal of clinical nutrition. 2013;97(4):677-688. Doi:10.3945/ajcn. 112.053116

8. Arora M, Nazar GP, Gupta VK, Perry CL, Reddy KS, Stigler MH. Association of breakfast intake with obesity, dietary and physical activity behavior among urban school-aged adolescents in Delhi, India: results of a cross-sectional study. BMC Public Health. 2012;12(1):881. Doi:10.1186/1471-2458-12-881

9. Eittah HF. Effect of breakfast skipping on young females' menstruation. Health Science Journal. 2014;8(4):469-484

10. Al-Oboudi LM. Impact of breakfast eating pattern on nutritional status, glucose level, iron status in blood and test grades among upper primary school girls in Riyadh City, Saudi Arabia. Pakistan Journal of Nutrition. 2010; 9(2):106-111.

11. Nurul-Fadhilah A, Teo PS, Huybrechts I, Foo LH. Infrequent breakfast consumption is associated with higher body adiposity and abdominal obesity in Malaysian schoolaged adolescents. PloS one. 2013 Mar 8;8(3):e59297. Doi:10.1371/journal. pone.0059297

12. Pendergast FJ, Livingstone KM, Worsley A, McNaughton SA. Correlates of meal skipping in young adults: a systematic review. International Journal of Behavioral 
Nutrition and Physical Activity. 2016;13(1):125. Doi:10.1186/s12966016-0451-1

13. Di Giuseppe R, Di Castelnuovo A, Melegari C, De Lucia F, Santimone I, Sciarretta A, et al. Typical breakfast food consumption and risk factors for cardiovascular disease in a large sample of Italian adults. Nutrition, Metabolism and Cardiovascular Diseases. 2012;22(4):347-354. Doi:10.1016/ j.numecd.2010.07.006

14. Tee $L$, Botha $C$, Laubscher $R$, Jerling J. The intake and quality of breakfast consumption in adolescents attending public secondary schools in the North West province, South Africa. South African journal of clinical nutrition. 2015;28(2):81-88. Doi:10.1080/ 16070658.2015.11734536

15. Mohiuddin AK. Skipping breakfast everyday keeps well-being away. Research \& Reviews: Journal of Dairy Science and Technology. 2019;7(3):20-30. DOI: 10.37591 /rrjodst.v7i3.1820

16. Lim SL, Canavarro C, Zaw MH, Zhu F, Loke WC, Chan YH, Yeoh KG. Irregular meal timing is associated with helicobacter pylori infection and gastritis. International Scholarly Research Notices. 2013. Doi.10.5402/2013/714970

17. Nas A, Mirza N, Hägele F, Kahlhöfer J, Keller J, Rising R, et al. Impact of breakfast skipping compared with dinner skipping on regulation of energy balance and metabolic risk. The American journal of clinical nutrition. 2017;105(6):13511361.
18. Jeneta JG. Effect of breakfast in body mass index among college going students. Journal of Pharmaceutical Sciences and Research. 2016;8(6):545-551

19. Mahoney CR, Taylor HA, Kanarek RB, Samuel P. Effect of breakfast composition on cognitive processes in elementary school children. Physiology \& behavior. 2005;85(5):635-645. Doi:10.1016/ j.physbeh.2005.06.023

20. Rani H, Ueno M, Zaitsu T, Kawaguchi Y. Oral malodour among adolescents and its association with health behaviour and oral health status. International Journal of Dental Hygiene. 2016;14(2):135-141. Doi:10.1111/idh.12160.

21. Kapantais E, Chala E, Kaklamanou D, Lanaras L, Kaklamanou M, Tzotzas T. Breakfast skipping and its relation to BMI and health-compromising behaviours among Greek adolescents. Public Health Nutrition. 2011;14(1):101-108. DOI: $10.1017 / \mathrm{S} 1368980010000765$

\section{Authors' Contribution:}

Noor Fatima: Study Design, Manuscript writing and proof reading.

Zirwa Noor: Over all Supervision of data collection, analysis and manuscript writing.

Swaira Shafique: Help in data collection analysis and final draft of study.

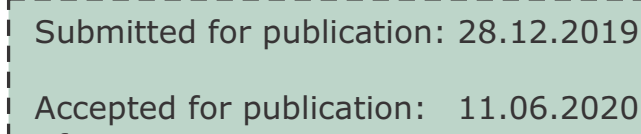

